\begin{tabular}{c} 
International Journal of Engineering \& Technology, $7(4.1)(2018) 118-123$ \\
International Journal of Engineering \& Technology \\
WPC \\
Website: www.sciencepubco.com/index.php/IJET \\
Research paperer \\
\hline
\end{tabular}

\title{
Determination of Perception and Adaptive Capacity towards Climate Change among Paddy Farmers in State of Kelantan, Malaysia
}

\author{
Nik Anis Nik Abdullah, Zalina Zahid*, Siti Aida Sheikh Hussin, Siti Shaliza Mohd Khairi \\ Centre for Statistical and Decision Science Studies, Faculty of Computer and Mathematical Sciences, \\ Universiti Teknologi MARA, 40450 Shah Alam, Selangor Darul Ehsan, Malaysia. \\ *Corresponding author E-mail: zalina@tmsk.uitm.edu.my
}

\begin{abstract}
Rapid changes in the climatic factors affect paddy farming in Malaysia. As Kelantan is the most vulnerable state to climate variations, its paddy production is negatively affected. Proper mitigation and adaptation approach can reduce paddy farmers' vulnerability to climate change. Hence, it is important to the paddy farmers to cope with climate change by having the right perception to ensure farmers take the right decisions on dealing with climate change. There are four objectives of this study which include estimating the trend of climate change in Kelantan using Mann-Kendall test, determining paddy farmers' perceptions towards climate change, measuring paddy farmers' adaptive capability using Analytic Hierarchy Process (AHP) and ascertaining associated factors of the adaptive capacity of paddy farmers using Binary Logistic Regression. Results showed that majority (85.9\%) of paddy farmers in Kelantan perceived changes in climate but only $62.9 \%$ of paddy farmers were highly adaptive towards climate change. Finally, age, monthly income, and district were found to be significantly associated with paddy farmers' adaptive capacity towards climate change. Although, most paddy farmers in Kelantan were highly adaptive towards climate change, government and related agencies still need to take some efforts and initiatives to enhance the farmers' adaptation towards climate change.
\end{abstract}

Keywords: adaptive capacity; perception; climate change; Analytic Hierarchy Process; Logistic Regression.

\section{Introduction}

Climate change refers to the shift in the global weather phenomena which is commonly linked to an increase in global average temperatures. Malaysia, located in South Asia, is currently experiencing climate change, as evidenced by the increase in the number of warm nights in some parts of Malaysia by more than $90 \%$ [1] with overall temperature is expected to have an increment between $0.6{ }^{\circ} \mathrm{C}$ and $4.5^{\circ} \mathrm{C}$ by 2060 [2]. Countries in South Asia have been identified as having the highest proportion of sectors which are dangerously exposed to the changes in climate [3]. In Malaysia, climate change was found to pose high risk to the agricultural sector. Its crop yields were estimated to drop around $10 \%$ to $15 \%$ yearly [4] from the consequences of climatic change factors specifically in terms of rain invariability. Paddy farming as part of the main agricultural activities is sensitive to climate change, making paddy farmers as the most vulnerable and easily affected by climate change. As climate change is a natural cycle in the Earth' climate, there is nothing that can be done to stop climate change from happening. Even with the presence of advanced technology nowadays, the effect of climate change on mankind could not be stopped. Hence, the only possible way to handle climate change is to deal with it.

Adaptation has been identified as an effective measure to deal with climate change. Adaptive capacity is defined as the ability of paddy farmers to adapt to any changes in environment surrounding the farmers and varies according to various associated factors. The enhancement of adaptive capacity is an effective measure to facilitate the adaptation to climate change and variability especially for vulnerable groups such as small-scale paddy farmers in developing countries [3]. Having the right perception on climate change will lead the paddy farmers to take the right decisions in dealing with climate change. Only when paddy farmers have the right perception on climate change then government and related agricultural agencies can intervene to guide and assist farmers in dealing with the changes in climate change.

Malaysia experiences a wet and humid tropical climate throughout the year ([5-9]). According to [10], Kelantan was found to be the most vulnerable to climate variations among all states in Peninsular Malaysia, based on climate change vulnerability index, with a score of 0.7061 out of 1.0. It was exposed to several risks which include land elevation, water supply, telecommunications coverage, economic growth and health issues. This implies that paddy farmers in Kelantan are facing problems with the unpredictable climate. Due to the unstable and shifts in the climate of Kelantan, paddy farmers face many challenges so that they can be adaptive towards climate change and variability. Number of studies $[11,12]$ was found to focus on the sustainability practices of paddy farmers in Kelantan, however none concentrates on investigating the perception and adaptive capacity of paddy farmers in Kelantan.

Hence, this study aims to estimate the trend of climate change in Kelantan, to determine the perception paddy farmers towards climate change in Kelantan, to measure the level of adaptive capacity of paddy farmers towards climate change in Kelantan, and to determine the factors associated with the adaptive capacity of paddy farmers towards climate change in Kelantan using combinations of 
several statistical techniques. In this study, the indicators of adaptive capacity were determined based on the framework of sustainable livelihood (SL). This framework searches for better understanding on the factors that affect poor people's livelihoods and the association with the factors [13]. Meanwhile, the items in adaptive capacity were adopted from $[14,15]$.

\section{Method of analysis}

\subsection{Study Site, Respondents, and Method of Gathering Data}

This study was conducted in Kelantan, covering five different districts i.e. Bachok, Kota Bharu, Pasir Mas, Pasir Puteh, and Tumpat. Areas under these districts were involved in paddy plantation activities under the management of Kemubu Agricultural Development Authority (KADA). Meanwhile, two types of data consisting of primary data and secondary data, were used in this study. The collection of primary data involved two groups of respondents. The first group consisted of a panel of three experts on paddy farming, purposively chosen to provide ratings on the relative importance of the different indicators of adaptive capacity. The ratings were elicited using the pairwise comparison questionnaire. These experts' ratings were then used to generate the weights of each indicator using Analytic Hierarchy Process (AHP). Then, the second group of respondents, consisting of 383 paddy farmers in Kelantan were selected using stratified random sampling. Under a cross-sectional survey, information on the paddy farmers' perception and adaptive capacity towards climate change were obtained through interviews. Meanwhile, the secondary data involving climatic records of rainfall and temperature in Kelantan were obtained from Malaysian Meteorological Department, covering period in 1972 to 2017 based on three weather stations; Gong Kedak, Kota Bharu, and Kuala Krai. These data were used to estimate the trend of climate of Kelantan.

\subsection{Estimation of Trend using Mann-Kendall (M-K) Test}

The trend of climate change in Kelantan was analyzed based on climatic records of rainfall and temperature from 1970 to 2017 using data from three weather stations. In particular, Mann-Kendall (MK) Trend Test was used to test the null hypothesis $H_{0}$ of observations $x_{i}$ follows no trend versus the alternative hypothesis $H_{1}$, of where observations $x_{i}$ follow an increasing or decreasing monotonic trend. The M-K test statistic, $\mathrm{S}$ is calculated based on the following formula:

$$
S=\sum_{k=1}^{n-1} \sum_{j=k+1}^{n} \operatorname{sign}\left(x_{j}-x_{k}\right)
$$

A set of time series $x_{k}$, is ordered based on $k=1,2, \ldots, \mathrm{n}$. Then, each data point is compared with data point $x_{k}$, referred as the reference point, so that:

$$
\operatorname{Sign}\left(x_{j}-x_{k}\right)=\left\{\begin{array}{ccc}
1 & \text { if } & x_{j}-x_{k}>0 \\
0 & \text { if } & x_{j}-x_{k}=0 \\
-1 & \text { if } & x_{j}-x_{k}<0
\end{array}\right.
$$

When the data size, $n \geq 8$, the statistic, $S$ is assumed to follow normal distribution with

$$
E(S)=0
$$

and

$$
\operatorname{Var}(S)=\frac{1}{18}\left[n(n-1)(2 n+5)-\sum_{p=1}^{q} t_{p}\left(t_{p}-1\right)\left(2 t_{p}+5\right)\right]
$$

Where $q$ is defined as the number of tied groups and $t_{p}$ is the number of point values in the $p^{\text {th }}$ group. Meanwhile, the $\mathrm{Z}$ variable, i.e. the standardized normal variable, is computed based on the values of $S$ and $\operatorname{Var}(S)$ as follows:

$Z=\left\{\begin{array}{ccc}\frac{S-1}{\sqrt{\operatorname{Var}(S)}} & \text { if } & S>0 \\ 0 & \text { if } & S=0 \\ \frac{S+1}{\sqrt{\operatorname{Var}(S)}} & \text { if } & S<1\end{array}\right.$

Positive $Z$ implies that there is an upward trend and vice-versa. Further statistical test is needed to confirm whether the upward or downward monotone trend is significant or not. A two-tailed test involves rejection of $H_{0}$ when $|Z|$ is larger than $Z_{1-\frac{\alpha}{2}}$ at $\alpha$ level of significance.

\subsubsection{The Sen's Estimator of Slope}

It is quite common that some seen trends are found not to be statistically significant even though it is expected [16]. In this study, linear trend analysis i.e. Sen's slope method is applied to measure the trend's magnitude. The computation of the slope $\left(Q_{i}\right)$ for all data pairs is based on [17] defined as follows:

$$
Q_{i}=\frac{x_{j}-x_{k}}{j-k} \quad \text { for } \quad i=1,2,3, \ldots, N
$$

Let $x_{j}$ and $x_{k}$ be data points at time $\mathrm{j}$ and $\mathrm{k}$ (where $\mathrm{j}>\mathrm{k}$ ). Meanwhile, let the median for all $\mathrm{N}$ values referring to $Q_{i}$ is denoted as Sen's slope's estimator, and the value was defined as:

$$
Q_{i}=T_{N+\frac{1}{2}} \text {, when } \mathrm{N} \text { is odd }
$$

$$
Q_{i}=\frac{1}{2}\left(T_{\frac{N}{2}}+T_{\frac{N+2}{2}}\right) \text {, when } \mathrm{N} \text { is even }
$$

If $Q_{i}$ has a positive sign then it indicates an upward or increasing trend but if $Q_{i}$ displays negative sign then it shows that there is a downward or decreasing trend in the time series.

\subsection{Measuring Adaptive Capacity using Analytic Hierar- chy Process (AHP)}

Analytical Hierarchy Process (AHP) is a multi-criteria decisionmaking method that models the complexity of decision problem, incorporating both quantitative and qualitative factors [18]. AHP 
develops scores where these values can be used to rank each decision based on the agreement between the alternative and the criteria of the decision maker. Specifically, AHP is utilized to assess how each indicator of adaptive capacity (human resources, physical resources, financial resources, information, and livelihood diversity) contributes to the overall adaptive capacity levels as perceived by the key informants.

\subsubsection{Pairwise Comparison Matrix}

A pairwise comparison matrix for the relative importance between each pair of alternatives was developed. A group of panels which consisted of five experts, chosen purposively were asked to provide ratings on the relative importance of the different adaptive capacity indicators and sub-indicators of adaptive capacity. The ratings were derived by using the pairwise comparisons questionnaire scale, which comes from the AHP method. Table 1 provides the value of pairwise comparisons based on Saaty's AHP fundamental scale.

Table 1. Saaty's AHP Scale for Pairwise Comparisons

\begin{tabular}{cll}
$\begin{array}{c}\text { Numerical } \\
\text { Values }\end{array}$ & \multicolumn{1}{c}{ Verbal Scale } & \multicolumn{1}{c}{ Explanation } \\
\hline $\mathbf{1}$ & $\begin{array}{l}\text { Equal importance of both } \\
\text { elements }\end{array}$ & $\begin{array}{l}\text { Two elements contribute } \\
\text { equally }\end{array}$ \\
\hline $\mathbf{3}$ & $\begin{array}{l}\text { Moderate importance of } \\
\text { one element over the other }\end{array}$ & $\begin{array}{l}\text { Experience and judgment } \\
\text { favor one element over } \\
\text { another }\end{array}$ \\
\hline $\mathbf{5}$ & $\begin{array}{l}\text { Strong importance of one } \\
\text { element over the other }\end{array}$ & $\begin{array}{l}\text { An element is strongly fa- } \\
\text { vored }\end{array}$ \\
\hline $\mathbf{7}$ & $\begin{array}{l}\text { Very strong importance of } \\
\text { one element over the other }\end{array}$ & $\begin{array}{l}\text { An element is strongly } \\
\text { dominant }\end{array}$ \\
\hline $\mathbf{9}$ & $\begin{array}{l}\text { Extreme importance of } \\
\text { one element over the other }\end{array}$ & $\begin{array}{l}\text { An element is favored by } \\
\text { at least and order of mag- } \\
\text { nitude }\end{array}$ \\
\hline $\mathbf{2 , 4 , 6 , 8}$ & Intermediate values & $\begin{array}{l}\text { Used to compromise be- } \\
\text { tween two judgments }\end{array}$ \\
\hline
\end{tabular}

\subsubsection{Computation of Adaptive Capacity Index}

A numerical value that is the weighted performance score is utilized to form the basis of the decision on the selection [19]. A multiplicative model was used to develop the adaptive capacity scores for each paddy farmer, calculated as:

$$
A C=a_{1} H R+a_{2} P R+a_{3} F R+a_{4} I+a_{5} L D
$$

Where:

$\mathrm{AC}$ is the adaptive capacity scores for paddy farmer

$\alpha_{1}, \alpha_{2}, \ldots, \alpha_{5}$ is the weightage for each respective indicator of $\mathrm{AC}$

HR is the indicator score for human resources $\mathrm{PR}$ is the indicator score for physical resources FR is the indicator score financial resources I is the indicator score for information $\mathrm{LD}$ is the indicator score for livelihood diversity

The weighted indicators, based on Equation 7, for human resources (HR), physical resources (PR), financial resources (FR), information (I), and livelihood diversity (LD) were calculated based on the formulas [20] as follows:

$$
\begin{aligned}
& H R I=w \cdot H R_{1}+w \cdot H R_{2}+w \cdot H R_{3} \\
& P R I=w \cdot P R_{1}+w \cdot P R_{2}+w \cdot P R_{3}+w \cdot P R_{4} \\
& F R I=w \cdot F R_{1}+w \cdot F R_{2}+w \cdot F R_{3} \\
& I I=w \cdot I_{1}+w \cdot I_{2}+w \cdot I_{3}+w \cdot I_{4} \\
& L D I=w \cdot L D_{1}+w \cdot L D_{2}+w \cdot L D_{3}
\end{aligned}
$$

The indicator scores together with their corresponding weights were linearly combined to come up with one single index score ranging from zero to one to reflect the level of adaptive capacity.

\subsubsection{Classification of Adaptive Capacity's Scores}

The final step involved classifying the sores into three different levels of adaptive capacity which are low, moderate, and high. Table 2 shows the three categories of adaptive capacity which are based on the range levels referred from the previous study [21].

Table 2. Category Level of Adaptive Capacity Degree of AC Ranges of Indices for $\mathrm{AC}$

Low Adaptive Capacity $0.00-0.32$

Moderate Adaptive Capacity $0.33-0.66$

High Adaptive Capacity $0.67-1.00$

2.4 Fitting Binary Logistic Regression to Determine the Factors Associated with Paddy Farmers' Adaptive Capacity

This study applied binary logistic regression, to determine the factors that could be associated with the level of paddy farmers' adaptive capacity towards climate change. The choice of this model is based on the desired result "Adaptive Capacity" has two possible outcomes coded as 0 for moderate level and 1 for high level. The proposed model was:

$$
\begin{aligned}
\operatorname{logit}(p(x)) & =\log \left(\frac{P(y=1)}{1-P(y=1)}\right) \\
& =a+\beta_{1} x_{1}+\beta_{2} x_{2}+\beta_{3} x_{3}+\beta_{4} x_{4}+\beta_{5} x_{5}
\end{aligned}
$$

where:

$P(y=1)=$ probability of a farmer is highly adaptive

$\beta_{i}=$ contribution rates from each variable

$x_{i}=$ variables associated with adaptive capacity of farmer

$i=1,2,3,4,5$

\section{Results and Discussions}

\subsection{Determination of Trend in Climate Variability}

The Mann-Kendall (M-K) statistical test was used to determine the trend of climate variability in Kelantan in terms of rainfall and temperature based on three weather stations. These weather stations were chosen to represent Kelantan's climate as more than 30 years of data were recorded at these stations. The time period of the study is considered long enough to study the changes in climate [22]. Furthermore, this test also needs the time series to be assumed serially independent as the presence of autocorrelation in the time series may affect the accuracy of the estimation of the trend. Before applying $\mathrm{M}-\mathrm{K}$ test, the presence of auto-correlation was examined using:

a) Correlogram of Autocorrelation (ACF) plot and Partial Autocorrelation (PAF) plot; autocorrelation exists if the vertical spikes do not lie between the straight horizontal dotted blue lines in the plot.

b) Durbin-Watson test; autocorrelation exists of the p-value for Durbin-Watson test is equal or greater than 0.05 . 
The presence of autocorrelation was detected in temperature across the years from 1972 to 2017. Therefore Cochrane-Orcutt transformation procedure was applied on the data to remedy the problem. Hence, only after the autocorrelation was removed, the trend was analyzed. Table 3 shows the summary of trend analysis of Kelantan's climate, for both rainfall and temperature based on M-K test.

Table 3. Trend Estimation of Kelantan's Climate

\begin{tabular}{cccccc}
\hline $\begin{array}{c}\text { Compo- } \\
\text { nent }\end{array}$ & Station & $\begin{array}{c}\text { Tau } \\
(\mathbf{p}-\text { value })\end{array}$ & Trend & Slope & $\begin{array}{c}\text { Direction of } \\
\text { Trend }\end{array}$ \\
\hline \multirow{4}{*}{ Rainfall } & $\begin{array}{c}\text { Gong } \\
\text { Kedak }\end{array}$ & $\begin{array}{c}0.587 \\
(<0.001)\end{array}$ & Exist & 3.729 & Increasing \\
\cline { 2 - 6 } & $\begin{array}{c}\text { Kota } \\
\text { Bharu }\end{array}$ & $\begin{array}{c}0.099 \\
(0.324)\end{array}$ & $\begin{array}{c}\text { Do not } \\
\text { exist }\end{array}$ & - & - \\
\cline { 2 - 6 } & $\begin{array}{c}\text { Kuala } \\
\text { Krai }\end{array}$ & $\begin{array}{c}0.267 \\
(0.008)\end{array}$ & Exist & 3.293 & Increasing \\
\hline \multirow{4}{*}{ Temper- } \\
ature & $\begin{array}{c}\text { Gong } \\
\text { Kedak }\end{array}$ & $\begin{array}{c}1.000 \\
(<0.001)\end{array}$ & Exist & 0.005 & Increasing \\
\cline { 2 - 6 } & Bharu & $\begin{array}{c}1.000 \\
(<0.001)\end{array}$ & Exist & 0.019 & Increasing \\
\cline { 2 - 6 } & $\begin{array}{c}\text { Kuala } \\
\text { Krai }\end{array}$ & $\begin{array}{c}1.000 \\
(<0.001)\end{array}$ & Exist & 0.028 & Increasing \\
\hline
\end{tabular}

The results showed that there were existences of positive trends for rainfall in Gong Kedak and Kuala Krai but no significant trend of rainfall existed in Kota Bharu. Meanwhile, there was an existence of trend for temperature across all three weather stations. The trend for temperature in all three stations shows positive trend. Overall, it can be concluded that there were changes in the trend of rainfall and temperature in Kelantan over the years.

\subsection{Perception of Paddy Farmers towards Climate Change}

Perception of paddy farmers refers to how the farmers view the climate variability [23]. The indicators used to reflect the farmers' perception are based on study done by [24] and [25]. Table 4 displays the distribution of the perception of paddy farmers. It was found that $85.9 \%$ of the paddy farmers perceived climate's changes, while only $14.1 \%$ of the farmers did not perceive changes in climate change. Therefore, it can be said that majority of paddy farmers in Kelantan did perceive changes in climate. These results are in line with the trend analysis of climatic records of rainfall and temperature from 1970 until 2017, where there exists trend in climate change for both rainfall and temperature. It is only relevant to measure the paddy farmers' adaptive capacity only if the farmers perceived changes in Kelantan's climate. Since the obtained result indicates that majority of paddy farmers in Kelantan perceived changes in climate, it is appropriate for the level of adaptive capacity of paddy farmers to be measured.

Table 4. Distribution of Paddy Farmers' Perception

\begin{tabular}{ccc}
\hline Perception & Frequency & Percentage (\%) \\
\hline Do Not Perceive Changes & 54 & 14.1 \\
\hline Perceive Changes & 329 & 85.9 \\
\hline Total & 383 & 100.0 \\
\hline
\end{tabular}

\subsection{Weights of Adaptive Capacity}

Based on experts' opinion, priority importance of each indicator and sub-indicator of adaptive capacity was evaluated. These criteria were used to determine the level of adaptive capacity for each paddy farmer. The weight for the indicators and sub-indicators is shown in Figure 1.

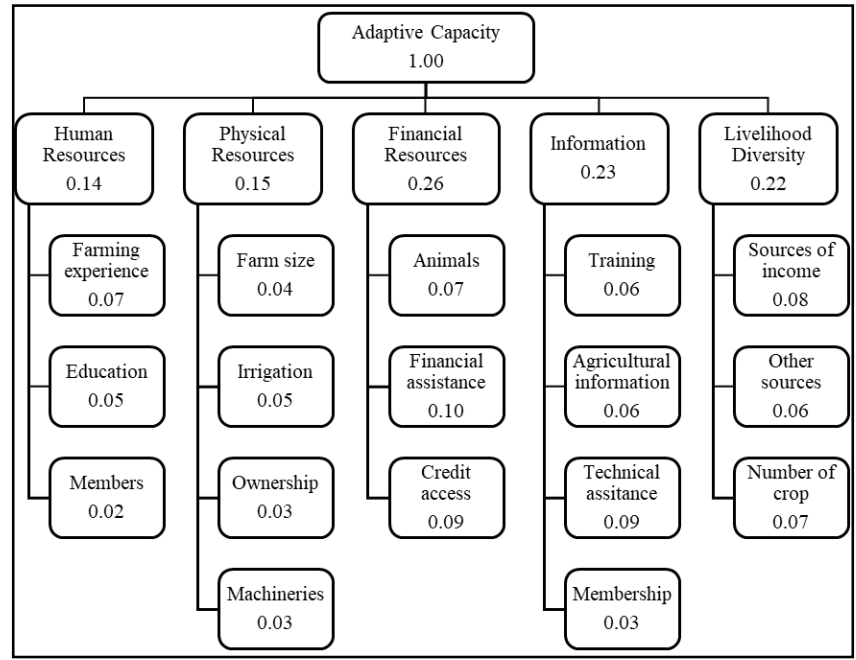

Fig 1. Weights of Adaptive Capacity

Based on the experts' opinion, the most important indicator for adaptive capacity is financial resources. Financial resources scored the largest weight from experts as the experts believed that adaptation towards climate change requires monetary expenditures. Furthermore, higher financial resources make possible the acquirement of physical and information resources. Information was ranked second as experts believed that accurate and enough knowledge is important for farmers to come up with effective adaptation strategies. These weights are then multiplied with respective answers chosen by farmers to obtain the score of adaptive capacity for each farmer.

\subsection{Levels of Adaptive Capacity}

The scores obtained were standardized to remove potential issues related to using indicators measured at different scales in order to categorize farmers into respective level of adaptive capacity, based on the standardized scores obtained. The categorization of farmers into respective level of adaptive capacity was based on the cut-off value as indicated in Table 2 .

After the categorization, it was found that paddy farmers in Kelantan are either moderately or highly adaptive towards climate change. Table 5 shows the frequency and percentage of farmers by levels of adaptive capacity. It can be shown that $37.9 \%$ of the paddy farmers are moderately adaptive towards climate change with the average score of 0.59 while $62.1 \%$ of the paddy farmers are highly adaptive towards climate change with the average score of 0.77 .

Table 5. Distribution of Paddy Farmers by Levels of AC

\begin{tabular}{ccccc}
\hline $\begin{array}{c}\text { Level of } \\
\text { Adap- } \\
\text { tive Ca- } \\
\text { pacity }\end{array}$ & $\begin{array}{c}\text { Ranges of } \\
\text { Indices for } \\
\text { Adaptive } \\
\text { Capacity }\end{array}$ & Frequency & $\begin{array}{c}\text { Percentage } \\
(\%)\end{array}$ & $\begin{array}{c}\text { Average } \\
\text { Adaptive } \\
\text { Capacity } \\
\text { Scores }\end{array}$ \\
\hline Moderate & $0.00-0.32$ & 145 & 37.9 & 0.59 \\
\hline High & $0.33-0.66$ & 238 & 62.1 & 0.77 \\
\hline Total & $0.67-1.00$ & 383 & 100.0 & \\
\hline
\end{tabular}

\subsection{Determination of the Factors Associated with Paddy Farmers using Binary Logistic Regression}

Before developing the model, the assumptions were initially tested for any presence of outlier and multicollinearity. It was found that there is no presence of outlier and multicollinearity. Hence, Binary Logistic regression was performed. Initially, analysis using binary logistic regression to determine the significant factor that associates significantly with paddy farmers' adaptive capacity towards climate change was performed by including all the predictor variables which are gender of paddy farmers (gender), age of paddy farmers (age), marital status of paddy farmers (marital status), monthly income of paddy farmers (income), and the district in which paddy 
farmers reside (district). After the significant predictor variables that associates significantly with paddy farmers' adaptive capacity was determined, the analysis using binary logistic regression was performed again by including only the significant predictor variables. Table 6 shows the summary of predictive model on factors associated with the adaptive capacity of paddy farmers (including only significant predictor variables).

Table 6. Summary for Predictive Model on Factors Associated with Paddy Farmers' Adaptive Capacity

\begin{tabular}{ccccccc}
\hline Variable & $\mathbf{B}$ & S.E. & Wald & df & Sig. & $\operatorname{Exp(B)}$ \\
\hline Age & 0.021 & 0.009 & 4.842 & 1 & $0.028^{*}$ & 1.021 \\
\hline Income & & & 13.785 & 4 & $0.008^{*}$ & \\
\hline Income (1) & 0.146 & 0.262 & 0.313 & 1 & 0.576 & 1.158 \\
\hline Income (2) & 0.754 & 0.372 & 4.121 & 1 & $0.042^{*}$ & 2.126 \\
\hline Income (3) & 1.579 & 0.593 & 7.095 & 1 & $0.008^{*}$ & 4.852 \\
\hline Income (4) & 1.816 & 0.833 & 4.752 & 1 & $0.029^{*}$ & 6.148 \\
\hline District & & & 23.168 & 4 & $<0.001^{*}$ & \\
\hline District (1) & -0.411 & 0.375 & 1.201 & 1 & 0.273 & 0.663 \\
\hline District (2) & 0.501 & 0.349 & 2.063 & 1 & 0.151 & 1.650 \\
\hline District (3) & 0.534 & 0.379 & 1.980 & 1 & 0.159 & 1.705 \\
\hline District (4) & 1.534 & 0.458 & 11.204 & 1 & $0.001^{*}$ & 4.637 \\
\hline Constant & -1.25 & 0.631 & 3.927 & 1 & 0.048 & 0.287 \\
\hline Significant & 0.05 & & & & &
\end{tabular}

*Significant at 0.05

It was observed that the significant associated variables with the level of adaptive capacity among paddy farmers towards climate change in Kelantan include age of paddy farmers (age), monthly income of paddy farmers (income), and the district in which paddy farmers reside (district). Since the variables income and district were categorical, dummy variables were created for these variables. The reference variable for income was the monthly income between RM0 to RM2000 while the reference variable for district was Tumpat. Age of paddy farmers had a positive relationship with the level of adaptive capacity (1.021). The implication is that for every one year' increases in the age of paddy farmers, the likelihood that the paddy farmers to be highly adaptive was 2.1 percent more as compared to moderately adaptive towards climate change in Kelan$\tan$.

Table 6 also shows that there is a positive relationship between paddy farmers whose monthly incomes are between RM2000 and RM3000 and their level of adaptive capacity (0.754). Paddy farmers whose monthly income is between than RM1000 and RM2000 are 2.1 times more likely to be highly adaptive towards climate change compares to paddy farmers whose incomes are lower than RM2000. Furthermore, there is also a positive relationship between paddy farmers whose monthly income lies between RM2000 to RM3000 and their level of adaptive capacity (1.579). Paddy farmers whose monthly income lies between RM3000 and RM4000 are 1.6 times more likely to be highly adaptive towards climate change compares to paddy farmers whose incomes are less than RM1000. Lastly, paddy farmers whose monthly income is above RM4000 are 6.2 times more likely to be highly adaptive towards climate change compares to paddy farmers whose incomes are less than RM1000.

Further results from Table 6 also indicate the districts in which paddy farmers reside have positive relationship with the level of adaptive capacity towards climate change in Kelantan (1.534). Paddy farmers that reside in Pasir Puteh are 4.637 times more likely to be highly adaptive towards climate change compares to paddy farmers who live in Tumpat. This is expected as Tumpat has the highest percentages of the urban hard-core poor residences as compared to other districts in Kelantan [26].

\section{Conclusion}

Paddy farmers in five districts of Kelantan; Bachok, Kota Bharu, Pasir Mas, Pasir Puteh, and Tumpat were asked if they had observed any changes in temperature and rainfall in Kelantan. The result indicates that $85.9 \%$ of the paddy farmers perceived variations in rainfall and temperature. These results are in line with the climatic data records of rainfall and temperature in Kelantan. The statistical analysis of rainfall from 1970 to 2017 in three weather stations; Gong Kedak, Kota Bharu, and Kuala Krai had shown the existence of trend in Kelantan's climate. The existence of trend in Kelantan's climate of rainfall and temperature are significant. This is due to the trend of temperature is increasing from year after year. The same goes to rainfall, as it signifies an increasing trend in Kelantan's rainfall. To find out that paddy farmers in Kelantan do perceives changes in Kelantan's climate make it possible to measure the level of adaptive capacity of paddy farmers towards climate change. Although more than half of the paddy farmers in Kelantan are highly adaptive towards climate change, paddy farmers in different district of Kelantan adapt to climate change differently. In addition, the analysis using binary logistic regression highlighted age of paddy farmers, monthly income of paddy farmers, and the district in which paddy farmers reside as the factors that associated with the level of adaptive capacity significantly. These findings are in line with the previous studies ([15], [21], [25]). Furthermore, the findings could assist KADA and agricultural authorities in Kelantan to take appropriate measures in ensuring paddy farmers in Kelantan to be highly adaptive towards the changes in climate. It is also recommended that further studies to be pursued on other factors that can facilitate adaptive capacity of paddy farmers.

\section{Acknowledgements}

The authors would like to thank Universiti Teknologi MARA (UiTM) for financially supporting this research under the LESTARI Research Grant Scheme, Code: 600-IRMI/MyRA 5/3/LESTARI (0151/2016).

\section{References}

[1] M.S, Kwan, F.T, Tanggang and L. Juneng, "Projected changes of future climate extremes in Malaysia", Paper presented at National Symposium on Climate Change, Putrajaya, Malaysia, (2011).

[2] IPCC, "Impacts, Adaptation and Vulnerability: A Contribution of the Working Group II to the Third Assessment Report of the Intergovernmental Panel on Climate Change (IPCC)", (2001), available online: https://www.ipcc.ch/pdf/assessment-eport/ar4/wg2/ar4 _wg2_full_report.pdf., last visit: 17.01.2018.

[3] IPCC, "Impacts, Adaptation and Vulnerability". (2007), available online: https://www.ipcc.ch/pdf /assessment-report/ar4/wg2/ar4_wg2_full_report.pdf., last visit: 17.01.2018.

[4] N. Shamil, (2018, March 15), Climate change affects us, Star Online, retrieved from http:/www. www.thestar.com.my/opinion/letters/2018/03/15/climate-change-affects-us.

[5] J. Suhaila, M.D. Sayang and W.Z.W, Zawiah and A,A. Jemain, Spatial patterns and trends of daily rainfall regime in Peninsular Malaysia during the southwest and northeast monsoons: 1975-2004, Meteorology and Atmospheric Physics, vol. 110(1-2), pp. 1-18, 2010.

[6] W.Z.W. Zawiah, A.A. Jemain AA, K. Ibrahim, J. Suhaila J, and M.D. Sayang, "A comparative study of extreme rainfall in Peninsular Malaysia: with reference to partial duration and annual extreme series", Sains Malaysiana, vol. 38(5), pp. 751-760. 2009.

[7] W.Z.W. Zawiah, S. Jamaludin, M.D. Sayang, and A,A, Jemain, "Recent changes in extreme rainfall events in Peninsular Malaysia: 1971-2005”, Theoretical and Applied Climatology, vol. 99(3-4), pp. 303. 2010

[8] J. Suhaila, M.D. Sayang, W.Z.W. Zawiah, and A.A. Jemain, "Trends in Peninsular Malaysia rainfall data during the southwest monsoon and northeast monsoon seasons: 1975-2004", Sains Malaysiana, vol. 39(4), pp. 533-542. 2010.

[9] A, Ismail, Z. Zahid, S.A.S Hussin, and S.S.M Khairi, "Modelling the efficiency of paddy production in Peninsular Malaysia using Principal Component Analysis and Data Envelopment Analysis (PCADEA)", International Journal of Supply Chain Management, vol. 7(4), pp. 158-171. 2018.

[10] F.M. Wong, (2014), “Development of Climate Change Vulnerability Index for Peninsular Malaysia" (Master Dissertation), retrieved from http:// http://studentsrepo.um.edu.my/4858/1/Development_of_a_Climate_Change_Vulnerability_Index_for_Peninsular_Malaysia.pdf. 
[11] R. Terano, M. Zainalabidin, S.M. Nasir, and A.L. Ismail, "Farmers Sustainability Index: the case of paddy farmers in State of Kelantan, Malaysia", Journal of ISSAAS (International Society for Southeast Asian Agricultural Sciences), vol. 21, pp. 55-67. 2015.

[12] M. Zainalabidin, T. Rika, S. Juwaidah, and R. Golnaz, "Determinants of Paddy Farmers Unsustainability Farm", Paper presented at International Conference on Food, Agriculture and Natural, (2016)

[13] M. Adato, and R. Meinzen-Dick. (2002). Assessing the impact of agricultural research on poverty using the sustainable livelihoods framework: Citeseer.

[14] R.H. Abagat, E. Roxas, J.P. Talubo, and E, Abucay. (2017), Adaptation and Adaptive Capacity to Flooding of Farming Households: Insights from Mabitac, Laguna, Philippines, Climate, Disaster and Development Journal, 56-64, doi:10.18783/cddj.v002.i02.a06.H

[15] G. Defiesta, and C.L. Rapera, "Measuring Adaptive Capacity of Farmers to Climate Change and Variability: Application of a Composite Index to an Agricultural Community in Philippines", Journal of Environmental Science and Management, vol. 17(2), pp. 48-62. 2014.

[16] S. Yue, P. Pilon, and G. Cavadias, "Power of the Mann-Kendall and Spearman's Rho Tests for Detecting Monotonic Trends in Hydrological Series", Journal of Hydrology, vol. 259(1-4), pp. 254-271. 2002

[17] P.K. Sen, "Estimates of the Regression Coefficient Based on Kendall's Tau", Journal of the American Statistical Association, vol. 63(324), pp. 1379-1389. 1968

[18] T.L. Saaty, The Analytic Hierarchy Process: Planning, Priority Setting, Resource Allocation, New York: McGraw-Hill, (1980).

[19] M.E, Guler, "Incorporating Multi-criteria Considerations into Supplier Selection Problems using Analytical Hierarchy Process: A Case Study Journal of Yasar University", vol. 3(12), pp. 1787-1810. 2008

[20] Q. Zhu, T. Liu, H. Lin, J. Xiao, Y, Luo, W. Zeng, W. Ma, (2014) The Spatial Distribution of Health Vulnerability to Heat Waves in Guangdong Province, China. Global Health Action, 7(1), doi:10.3402/gha.v7.25051.

[21] F. Eyasmin, (2017), Perception of and Adaptive Capacities to Climate Change Adaptation Strategies and Their Effects on Rice Production: A Case of Pabna District, Bangladesh, Journal of Health and Environmental Research, 3(1), doi:10.11648/j.jher.20170301.12.

[22] M. Amirabadizadeh, Y.F. Huang, and T.S Lee, "Recent trends in temperature and precipitation in the Langat River basin, Malaysia", Advances in Meteorology, 2015.

[23] M. Wehbe, H. Eakin, R. Seiler, M. Vinocour, C. Avila, and C Maruto, (2006), Local Perspectives on Adaptation to Climate Change: Lessons from Mexico and Argentina, AIACC Working Paper No. 39, USA.

[24] M. Allahyari, S. Ghavami, M.Z. Daghighi MZ, A. Michailidis, S. Nastis S, (2016), Understanding Farmers' Perceptions and Adaptations to Precipitation and Temperature Variability: Evidence from Northern Iran, Climate, 4(4). doi:10.3390/cli4040058.

[25] B. Amdu, and A. Aeressa, (2013), African Technology Policy Studies Network, ATPS: Farmers' Perception and Adaptive Capacity to Climate Change and Variability in the Upper Catchment of Blue Nile, Ethiopia.

[26] S. Chamhuri, A. Ferdoushi, Z. Siti Zalikha, M.I. Nor Diana, M.M. Shahin, and B, Ahmad B, "Poverty Mapping and Assessing the Relationship between Poverty and Socio-demographic Characteristics of Households: A Study in Kelantan, Malaysia", Journal of Environmental Science and Technology, vol. 9 (6): pp. 407-416. 2016. 